\title{
THE CHEMISTRY AND BIOCHEMISTRY OF MYOCHRISINE
}

\author{
Colin J. L.Lock, Helen E. Howard-Lock, Walter F. Kean, \\ Daren J. LeBlanc and Zhixian Wang \\ Laboratories for Inorganic Medicine, Departments of Chemistry, Medicine and Pathology, \\ McMaster University, ABB-266A, Hamiton, ON L8S 4M1, Canada
}

\begin{abstract}
As part of our studies of the interaction of gold $(I)$ with thiols and other sulphur-containing molecules we have managed to isolate and characterize by $X$-ray crystallography, the first gold(I)-thiomalate complex. We shall describe this work and speculate on its significance to the nature of the gold drug myochrysine, and its mode of biochemical action.
\end{abstract}

